\title{
Chinese Undergraduates' Conceptions of Learning in Higher Education: A Phenomenographic Perspective
}

\author{
Xiantong Zhao \\ Department of Lifelong and Comparative Education, UCL Institute of Education, \\ London, United Kingdom \\ E-mail: zhaoxiantong1981@gmail.com
}

Received: April 11, 2015 Accepted: May 4, 2015 Published: May 10, 2015

doi:10.5296/ire.v3i2.7419 URL: http://dx.doi.org/10.5296/ire.v3i2.7419

\begin{abstract}
As a qualitative research approach, phenomenography has been widely employed to explore people's distinct conceptions of certain phenomena. By employing the approach, the present research aims to explore a group of Chinese undergraduates' $(n=17)$ conceptions of learning. Data has been collected through individual in-depth interview and followed a seven-step phenomenographic analytical process. Ultimately five conceptions are found, namely: learning as acquisition of knowledge and skills, application, understanding, seeing something in a different way, and continuous and informal education phenomena. The limitations as well as some implications for future research have been discussed at the end of the paper.
\end{abstract}

Keywords: Phenomenography; Conceptions of learning; Chinese students; Higher Education

\section{Introduction}

The research study is designed to explore the qualitatively different ways in which students conceptualize or understand learning. Conceptions of learning are a crucial issue for phenomenographic research, and its close relationship with approaches to learning and learning outcomes has been highlighted (Marton \& Booth, 1997). However, little has been done to uncover the Chinese undergraduates' conceptions of learning. Therefore, it is the aim of the present study to answer the predominant research question: What are the conceptions of learning held by a group of undergraduates? 


\section{The Context}

The research study was set out to determine Chinese undergraduates' conceptions of learning. Therefore, a university in Beijing was chosen as the context. The university was widely known for its excellence in the area of business education across this country. Seventeen students, who are pursuing studies in the International Economics and Trade (IET) program, volunteered to participate in the research. Established in 1999, the IET program aims at fostering international, innovative, and inter-disciplinary talents, along with good language skills and professional knowledge. IET graduates have proceeded to work in banks, giant trading companies, transnational corporations, and the government. Their professionalism is highly appreciated.

The IET is a four-year program for undergraduates, covering a wide range of international business-related curricula, such as: Political Economics, Microeconomics, Macroeconomics, Econometrics, International Economics, Public Finance, Accounting, Statistics, Principle of Management, General Theory of Civil and Commercial Law, International Trade, International Finance, International Investments, International Trade Practice, International Settlement, International Marketing, Risk Management \& Insurance and International Commercial Law.

It would be unrealistic, nor is the researcher's intention, to cover the entire country. Hence, the study can be viewed as a phenomenographic case study to get just a glimpse of what the conceptions would be in the Chinese context.

\section{Conceptions of Learning}

'Conception' is the basic unit of description in Phenomenography (Marton \& Pong, 2005). As Sandberg (2000) states: In phenomenography, "the term conception is used to refer to people's ways of experiencing or making sense of their world” (p. 12). It resembles "personal epistemologies: beliefs about the nature of knowledge and of coming to know" (Ellis et al., 2008, p. 268). The conception of learning "captures the way in which a person views learning, that is, what learning means to him/her” (Byrne \& Flood, 2004, p. 26).

Säljö's (1979) five qualitative different ways of conceptualizing learning is a pioneering work, and provides a foundation for the discovery of the most well-known six categories of conceptions of learning by Marton, Dall'Alba and Beaty (1993). The concrete explanation can be illustrated below (Table 1): 


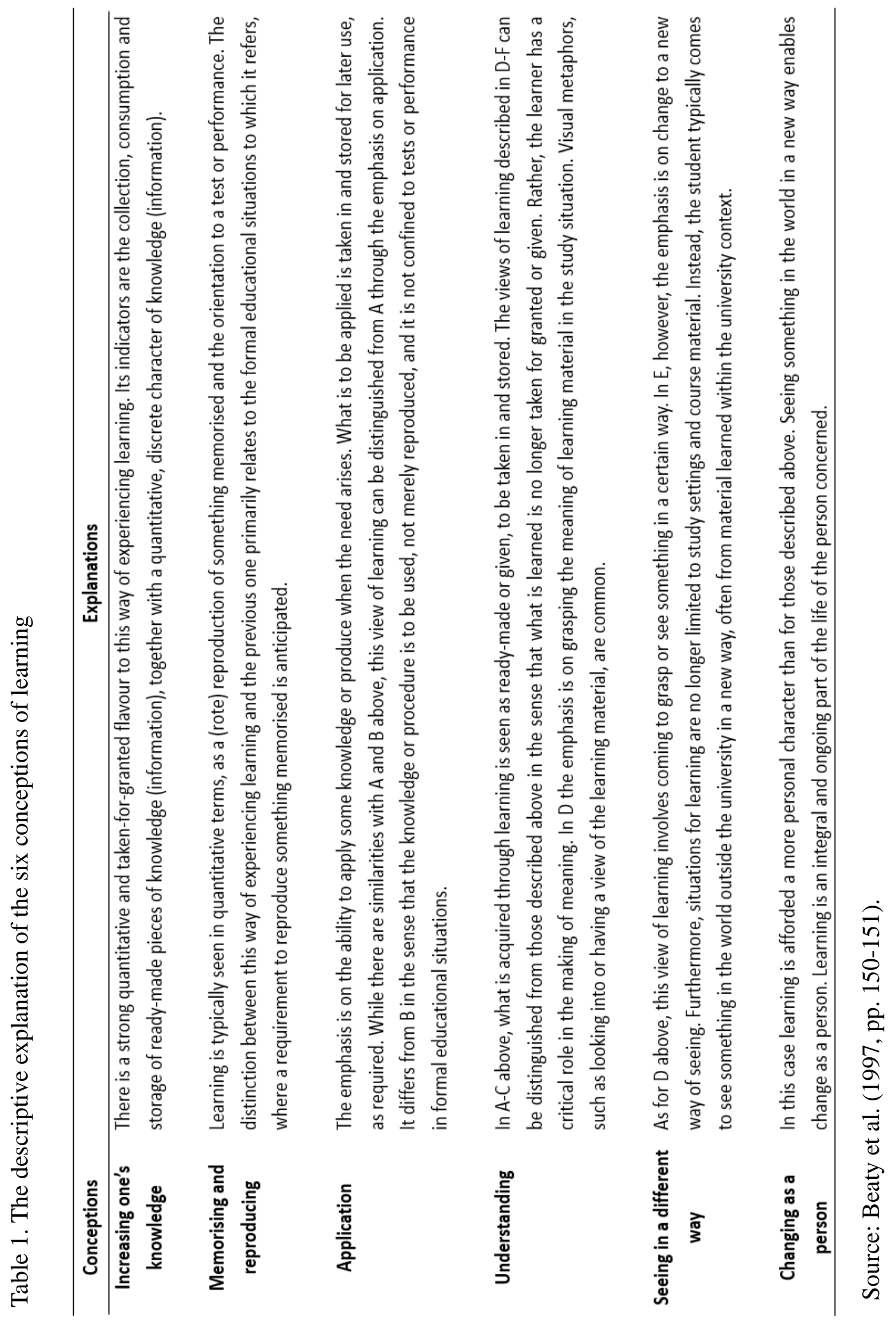


Conception of learning is a critical research area for phenomenographic studies. Its significance comes from its intimate relationship with learning approaches and outcomes, which has been proved by a number of researchers (Edmunds \& Richardson, 2009; Marton \& Booth, 1997; Van Rossum \& Schenk, 1984). Gibbs (1995) even contends that "it is possible to predict the quality of the learning outcomes directly from students' conceptions of learning” (p.23). A thorough understanding of how students conceptualize their learning has strong implications for improving learning (Asikainen et al., 2013).

Even if it seems as though results generated from phenomenographic research across decades of years are similar, they "cannot be taken to imply a universality of meaning with reference to learning” (Purdie \& Hattie, 2002, p. 18). As Säljö (1987) claims, learning is to "act within man-made institutions and to adapt to the particular definitions of learning that are valid in the educational environment in which one finds oneself” (p. 106). It would be unreasonable to separate learning activities from their educational environment or context. Different contexts might be impacted profoundly by distinct historical, social and cultural factors, which constitute the outcome of cross-cultural studies.

Within the Chinese context, however, one would hardly come across such phenomenographic studies aimed at uncovering university students' variations of conceptions of learning. The 'paradox of Chinese learners' - a contradictory relation between memorization and understanding - has attracted too much attention (Biggs, 1996; Marton \& Booth, 1997; Marton et al., 1997; Wen \& Marton, 1993). But arguably the range of research cannot be expanded if the researcher focused merely on memorization and understanding. In this sense, the conceptions of learning for Chinese undergraduates have yet to be revealed.

\section{Research Methodology}

\subsection{Phenomenography}

It was Ference Marton (1981) who first introduced phenomenography to the world of education. The term 'phenomenography' originated from two Greek words 'phainomenon' (appearance) and 'graphein' (description): Phenomenography is thus applied to describing things as they appear to us (Pang, 2003, p. 145). Marton (1994) defines phenomenography as: "the empirical study of the limreited number of qualitatively different ways in which various phenomena in, and aspects of, the world around us are experienced, conceptualized, understood, perceived and apprehended" (p. 4424). Svensson (1997) contends that phenomenography "represents a reaction against, and an alternative to, the then dominant tradition of positivistic, behavioristic and quantitative research” (p. 171).

In addition, Trigwell (2006) summarizes several key features of phenomenography. First, at the philosophical level it is non-dualistic, which is to say that meaning emerges within the relationship between individuals and phenomena. The argument is in sharp contrast with cognitivism, which separates people from reality. Second, phenomenography is a qualitative research approach while not a quantitative approach to study people's experiences and understandings of a particular concept or phenomenon. Third, it adopts a second-order perspective by researching subjects' own perceptions rather than showing researchers' 
personal understandings. Fourth, phenomenography seeks for the variations or differences, whereas other research tradition such as phenomenology looks for commonalities. Fifth, the approach believes that there are some internal relations among the finalized categories and it is the researcher's task to build up the logic relationship. Phenomenographers should not view these categories as fragmented and unrelated. The ultimate product of a typical phenomenographic research is the 'outcome space' (Marton \& Dahlgren, 1976), which is composed of various categories and relationships.

Doing phenomenographic studies, researchers are required to distinguish it from phenomenology. With Barnard et al.'s (1999) table, one could see the differences between the two.

Table 2. The relationship between phenomenography and phenomenology

\begin{tabular}{lc}
\hline $\begin{array}{l}\text { Phenomenography } \\
\text { The structure and meaning of a phenomenon } \\
\text { as experienced can be found in prereflective } \\
\text { and conceptual thought. }\end{array}$ & $\begin{array}{c}\text { A division is claimed between prereflective experi- } \\
\text { ence and conceptual thought. }\end{array}$ \\
$\begin{array}{l}\text { The aim is to describe variation in understand- } \\
\text { ing from a perspective that views ways of } \\
\text { experiencing phenomena as closed but not } \\
\text { finite. }\end{array}$ & $\begin{array}{c}\text { The aim is to clarify experiential foundations in } \\
\text { the form of a singular essence. }\end{array}$ \\
$\begin{array}{l}\text { An emphasize on collective meaning. } \\
\begin{array}{l}\text { A second-order perspective in which experi- } \\
\text { ence remains at the descriptive level of par- } \\
\text { ticipants' understanding, and research is } \\
\text { presented in a distinctive, empirical } \\
\text { manner. }\end{array}\end{array}$ & $\begin{array}{c}\text { An emphasis on individual experience. } \\
\text { in the psychological reduction of experience. }\end{array}$ \\
$\begin{array}{l}\text { Analysis leads to the identification of concep- } \\
\text { tions and outcome space. }\end{array}$ & $\begin{array}{c}\text { Analysis leads to the identification of meaning } \\
\text { units. }\end{array}$ \\
\hline
\end{tabular}

Source: Barnard et al., 1999, p. 214.

\subsection{Data Collection}

Conducting a semi-structured individual interview is a very prevalent method of data collection in phenomenography. On the one hand, the conversation would not go out of control as the main questions are already prescribed by the researcher. On the other hand, and to a large extent, it allows participants the freedom to express themselves. Moreover, the value of this method lies in the opportunity to ask follow-up questions, because "the follow-up prompts in a phenomenographic interview are often more important in eliciting underlying meaning than the primary questions” (Åkerlind, 2005b, p. 65).

The primary questions for the research include 'What do you mean by learning?', 'What are you trying to achieve while learning?', and 'How do you know when you have learnt something?'. All these questions have typical phenomenographic characteristics, yet they should also be complemented by follow-up questions if the study is to further generate even 


\section{Macrothink}

International Research in Education

ISSN 2327-5499

2015, Vol. 3, No. 2

more important data. These may involve questions such as: 'Could you explain further?', 'Could you give me an example?', 'Why do you say/do it that way?', etc. All the participants answered the interview questions in Chinese, which were translated into English in the analytical procedure.

Maximum variation sampling is a crucial method (Green, 2005) due to its interest in heterogeneity or diversity. Åkerlind, Bowden and Green (2005) claim that "[i]n phenomenography, small sample sizes with maximum variation sampling, that is, the selection of a research sample with a wide range of variation across key indicators (such as age, gender, experience, discipline areas and so on), is traditional” (p. 79). Consequently, the basic background information of volunteers was taken into account to guarantee the diversity of the group.

Finally a total of 17 students - five male students and twelve female students - volunteered to participate in the interview. The group also covered all the four grades, with 2 first-year students, 5 second-year students, 7 third-year students, and 3 fourth-year students. Table 3 below demonstrates some basic information of all the interviewees.

Table 3. Information of interviewees

\begin{tabular}{cccc}
\hline Student Number & Gender & Year of study & Age \\
\hline S1 & Female & 3 & 22 \\
S2 & Male & 3 & 22 \\
S3 & Female & 3 & 21 \\
S4 & Female & 3 & 23 \\
S5 & Female & 3 & 22 \\
S6 & Male & 3 & 23 \\
S7 & Female & 2 & 20 \\
S8 & Female & 2 & 21 \\
S9 & Female & 2 & 21 \\
S10 & Female & 3 & 21 \\
S11 & Male & 2 & 20 \\
S12 & Female & 1 & 19 \\
S13 & Male & 1 & 19 \\
S14 & Female & 2 & 19 \\
S15 & Female & 4 & 22 \\
S16 & Female & 4 & 21 \\
S17 & Male & 4 & 23 \\
\hline
\end{tabular}

\subsection{Data Analysis}

In order to make the process structured and facilitate manipulation, several researchers have 
produced and followed seven steps to analyze the data (Dahlgren \& Fallsberg, 1991; Khan, 2014; Sjöström \& Dahlgren, 2002). This research also followed the seven-step analytical method as follows. Initially I read the whole set of transcripts several times until I felt I had been familiar with all of them. The following step involved compiling students' answers to some questions and identifying the most important elements in answers. In Step 3 I selected related and meaningful quotes for the study and removed irrelevant data. Then I categorized similar answers into the same group and clarified the borders between the categories and revised the preliminary groups. After all of these, I also needed to give each category a name to highlight its nature and uniqueness. The final step was the construction of the outcome space.

In addition, there are also a number of critical issues faced during the analytical process. First, the researcher's own experience, some existing theories, and past research findings should be 'bracketed' in order to allow the categories to emerge from the original data. Second, analysis ought to be conducted at the collective level, which means the researcher should not indulge in focusing on just one individual's transcripts. Third, there are two contexts for each quote or excerpt (Marton, 1986). Consequently, it is expected that researchers interpret transcripts as faithfully as possible by consulting with the two contexts.

\subsection{Validity, Reliability and Generalizability}

As Åkerlind (2005b) contends, validity in phenomenography is "the extent to which a study is seen as investigating what it aimed to investigate, or the degree to which the research findings actually reflect the phenomenon being studied” (p. 330). Cope (2004) has proposed a comprehensive set of strategies to guarantee the validity and rigor of phenomenographic research, which is outlined below:

- The researcher's background is acknowledged;

- The means by which an unbiased sample was chosen is reported;

- In cases where convenience samples are used the characteristics of the participants should be clearly stated, providing a background for any attempt at applying the results in other contexts;

- The design of interview questions is justified;

- The strategies taken to collect unbiased data be included;

- Strategies used to approach data analysis with an open mind rather than imposing an existing structure be acknowledged;

- The data analysis method be detailed;

- The researcher accounts for the processes used to control and check interpretations made throughout analysis;

- The results are presented in a manner which permits informed scrutiny;

- Categories of description should be fully described and adequately illustrated with quotes (pp. 8-9). 
The reliability of phenomenographic research often refers to the extent to which some research findings and results made in a certain study can be produced again in other research works (Booth, 1992). Thus the notion of 'interjudge reliability' was invented to measure "the communicability of categories and thus gives the researcher information that someone else can see the same differences in the material as he or she has done” (Säljö, 1988, p. 45). Nonetheless Sandberg (1997) criticizes it for its positivistic and objectivist trace and ignorance of research procedures. The solution he proposed is the interpretative awareness, which means "to acknowledge and explicitly deal with our subjectivity throughout the research process instead of overlooking it” (ibid. p.209). As Cope (2004) explains, “[a] researcher is required to be aware of their interpretations during the research process and demonstrate how the interpretation processes have been controlled and checked” (p. 10).

Generalizability, or the external validity (Miyata \& Kai, 2009) examines "the extent to which one can expand the account of a specific population to other persons, times, or settings" (Maxwell, 1992, p. 293). It is a controversial issue in phenomenography. On the one hand, some authors (Kinnunen \& Simon, 2012; Osborne, 2011) have been suspicious of the introduction of this notion, for example, Åkerlind (2005a) claims that "phenomenographic research outcomes have been described as not enabling generalization from the sample group to the population represented by the group, because the sample is not representative of the population in the usual sense of the term" (p. 12). On the other hand, it is very common that some findings made from one phenomenographic study may also be obtained by other researchers (Marton \& Booth, 1997). According to Mertens and McLaughlin (2004) and Miyata and Kai (2009), generalizability or the external validity could be improved, and it is up to the researcher to "provide sufficient detail to enable the reader to make ... a judgement ... to determine the degree of similarity between the study site and the receiving context” (Mertens \& McLaughlin, 2004, p. 107).

\section{Findings}

In total, five conceptions have been found, namely: learning as acquisition of knowledge and skills, application, understanding, seeing something in a different way, and continuous and informal education phenomena.

\subsection{Conception A: Learning as Acquisition of Knowledge and Skills}

Only a small number of students held this low-level conception, which simply saw learning as something very general and vague. It seemed that they did not intend to explore the definition of learning; instead, they took it for granted. In other words, for them learning could explain learning, per se. Indeed, I was sometimes surprised by their answers to the question: 'What do you mean by learning?', because it appeared that they had never given any thought to such a question. In practice, however, students highly valued the quantum increase of knowledge, and they believed that it could be achieved through various methods like reading or taking notes. Their aim, and what they did, was to gather as much knowledge as possible without thinking about either the underlying meanings or relations thereof. In their perspective, therefore, knowledge was rather fragmented and unrelated. 
Learning is a process of information acquisition by means of teachers' instruction, reading from either textbooks and/or by using modern gadgets like cell phones. S3

Learning is acquiring knowledge. There are many approaches to learning and so is the content for learning. S5

Learning is a continuous process to keep updating yourself by absorbing new knowledge and truths. S16

Other subjects pointed out that skill acquisition too was important and was one of the key aims for pursuing university study.

I think the scope of learning is broad; you can learn the skills you have not grasped from life and books. I think it is more important to learn skills. S7

I think it is more about learning skills in universities, that is, how to survive and work. S8

The first is the knowledge of trade, and some business negotiation skills. S11

\subsection{Conception B: Learning as Application}

This conception is very complex due to the key word 'application', which refers to applying what has been learnt to various circumstances such as exercises, exams, and real life as a whole. Pillay and Boulton-Lewis (2000), contend that the complexity makes learning as an application an intriguing conception, in that "it was perceived in terms of being able to either perform a physical task or consider application as a means of contextualizing concepts” (p. 171).

The student-participants always talked about the positive interaction between application and knowledge. The aim lies not only in understanding the subject matter, but also in securing personal future benefits, probably on the career front. Some students initially only related application to their subject matters and personal research.

I feel I've come across this issue and I can apply it to my dissertation. ... The most important thing is [to apply it to ${ }^{1}$ dissertation and making slides... S4

Second, I can apply it to my research. If I succeeded, it would mean I have learnt it. S17

The university introduced software to learners, with the help of which students could apply what they had learnt to a series of tasks to better understand the subject matter, or the key concepts obtained. Many concepts might seem confusing without the application of the software.

For example, in the trade practice, they gave you a kind of software ... and you operated through it. They then gave you some money to help you set up your identity ... We had a theoretical course in the past, so we understood it when we used this operation. The first year was the theoretical course; the second year was practice/operation. S1

\footnotetext{
1 The bracketed words were added by me in the analytical process so that the participants' meaning could be fully and clearly presented.
} 
Nonetheless, a majority of participants discussed the application of knowledge in combination with real-life situations. They were thus able to contextualize the concepts, facts, theories, principles, models, procedures, and mathematical knowledge. As Marton and Booth (1997) claim, this conception "has application in focus in addition to getting the knowledge and storing it", and "the constraint that learning is confined to study situations has weakened, as the learner becomes prepared to consider the new acquisitions in other, as yet unspecified, contexts” (p. 37).

For example, the appreciation of the RMB, results in the increase of import, but why? This is very normal, but you have to use theory and numeric theory [to explain it]. S1

For example, if an international occurred; then we can consider the political and economic outcome of it in the light of what we've learnt. S3

You are able to solve some practical issues by applying your knowledge. This is the basic grasp. S5

... you are asked to use certain theory to explain something; for example, an international trade theory. You are required to discuss its influence on your country, and other regions, in combination with reality. S15

\subsection{Conception C: Learning as understanding}

Learning, according to this conception, is viewed "in terms of the learner grasping, or understanding an idea, a meaning; developing a conception of something” (Marton et al., 1993, p. 290). In other words, the focus of those who were holding this conception was based on the underlying meanings behind the knowledge. For example: How did an equation come about? What was the logic inside the theory? What was the mechanism between A and B?, etc. Students with this conception usually had strong motive to explore the rationales and principles within the knowledge system. In addition, they also intended to further internalize what they had learnt, as Marton and Booth (1997) contend, it "involves putting their newly gained knowledge not only into a context of the demands being made by the educational system of which they are a part, but also integrating it into their own worlds through comparing and contrasting” (p. 37). Participants with this conception played a very active role in their learning. It is also necessary to notice that this conception is "delimited to the study situation” (Marton et al., 1993, p. 291).

For example, each chapter is related to another, ... the teacher should connect them all together, that is, telling us why it was designed that way; why put one in the first chapter and another in the second chapter, so that we can better understand the meanings. ... Because they are interrelated and there is some logic applied. S13

For example, if you refer to a certain theory, I can think about its origin and implication, its relationship with others, how it comes about, what the mechanism is, how to evaluate it, what the pros and cons are ...Finally, you can understand it at a deeper level and internalize it as your own, or you can understand it to the extent that rote learning is unnecessary. S15

Understanding is to understand the logic; for example, the economic logic or the financial logic. You understand them and so, that is understanding. S16 
For example, I come across it while reading a paper and then I can understand it and its logic, even discover what the problem is, then I think I have learnt it. S17

Understanding could be demonstrated by explaining something to others (Byrne \& Flood, 2004). Some participants mentioned that they were often asked to explain theories and concepts to others for clarification, and they could do it. They believed that this was an effective way of showing that they were clear about the fundamental meanings.

Maybe [the knowledge] will not be applied, but you are able to explain it to others, that is, you can make an answer when asked by somebody. This is to say that you've learnt. S10

Others for example may ask you a question. Once you are able to answer, you understand it. $\quad$ S14

In this conception, the meaning-making process can also be reached by "integrating knowledge and understanding across subject areas and over time” (Byrne \& Flood, 2004, p. 33). Indeed, subjects' sayings also demonstrated that an even deeper understanding of learning was obtained with the connections formed within different aspects of a subject, and even among distinctive academic domains. Several participants expressed this and they frequently used a Chinese idiom (rong hui guan tong) to name it; the English meaning of which is: to bring knowledge of different courses or even academic domains (disciplines) together is to understand the subject matters thoroughly.

Initially, while learning something in a current course, students were able to recall some knowledge gained from other courses in the past, in that they needed it in order to understand the current issues. Because of the comprehensive nature of the program investigated; lecturers teaching, for example; people from the accounting and finance departments were often invited to deliver knowledge to these students. Thus the internal connection among different parts of a subject was built up.

...mm, the knowledge I've learnt, for example economics, microeconomics, macroeconomics, finance and international economic;, I didn't think they were useful at first. But we had to make a presentation in the international investment course and analyze a phenomenon, and it required us to just apply this knowledge. If you saw the phenomenon and associated it with that knowledge, it demonstrates you've learnt it. S1 I believe that all the courses are interconnected. ... All the courses are deepened by interrelation, repetition, and refining.... The courses in the third year of study depend on those covered during the first and second years of study. If you didn't learn them well in the first two years ... you may find them difficult to learn later. I think a course like say, economics, is interconnected to the other courses. S7

We had Management in the last semester and Organizational Behavior Studies in this semester. ... The two were different in terms of content ... but they were interconnected in many aspects. I'm taking an ACC course, which combines the knowledge of Management, Accounting, Macroeconomics, and Microeconomics. ... If you've learnt these courses ... it becomes easier, but if you haven't, you cannot understand it. S12 
Furthermore, there might be a connection between, and even among, various domains. One participant was looking for the link between IET knowledge, and some sociological and political theories. The student placed a great deal of value on the connection as she felt it might help broaden her horizon and thus, prove beneficial to her in future. It is certain that this learner would not attempt to explore this kind of external connection among different academic domains unless she obtained a deeper understanding and knowledge of IET.

Take finance and economics for example. Although they are applied disciplines, I think they should be connected to sociology. I think we should be taught about some concepts of how to understand the whole society, as well as some principles, including democracy and the operational law of the society. Not just the economical aspect, but even sociology and ethics ought to be included. S16

\subsection{Conception D: Learning as Seeing Something in a Different Way}

In this conception, "it is the change that is emphasized: the learner is changing his or her way of thinking about something, changing the conception of something” (Marton et al., 1993, p. 290). Students' attitudes towards learning could be depicted as more personal and reality-oriented (less subject-matter oriented), and with active learning approaching the central position, it implied that learners were becoming more critical and autonomous (Van Rossum et al., 1985). A definite transformation from reproductive learning to constrictive learning was observed to be underway. In addition, in this conception, "learning (or rather, its effect), is located in the world (beyond the study situation)" (Marton et al., 1993, p. 291). In the first place, many felt that their ways of thinking were changing, i.e., they were able to consider something from a different perspective.

We're undergraduates and the most predominant feature is changing the way of our thinking. That is, when thinking about some issues, you consider yourself a professional or a person who has already done some studies and grasped some knowledge. This is terribly important.... I have personally changed my perception. S2

I think it's a change in the way you view things. While learning, you find something you did not previously see it as you are doing now. Maybe somebody taught you this. ... You analyze things by means of what you've learned, and [discover] your viewpoint now is different from that of the past and it's wider and deeper. ... I think that is the point of attending universities, from a learning standpoint... S6

Therefore, they developed what was referred to as the 'economic model of thought', 'economic perspective', 'economic sensitivity', or even 'economic accomplishment'. All of these would not have been fostered if they had pursued a totally different academic domain (e.g., law, or literature).

I think it may be a thinking model, a habit. Because I'm studying economics, I am more aware of what I'm viewing, say, while watching the economic news. You feel you have learnt nothing, ... but when you look at those news and events, ... you think about the impact it will bring about,... I discover that this may be my way of looking at it from an economic standpoint. ... I think this is the economic sensitivity I have gained... Because 
I'm impacted by the economic theories and teaching, I view something from this angle chronically... S5

That is, thinking about some issues from an economic perspective. You do not view it in a simple manner; you discover the underlying economic law behind it. S7

I have the economic accomplishment that others perhaps would never have if they learned different subjects. [By economic accomplishment, I mean] thinking about issues in an economic way. With some basic economic knowledge, my brain works when I read economics-related material. If my major was law or literature, I would not have been able to understand economics. S10

Some students said that they further formed an opinion after they observed and analyzed some phenomena around them. It helped them to explain things independently, and thus, they became independent thinkers. As one said, a person lives to have his/her own viewpoint. But it was a process built up on the basis of existing knowledge and others' wisdom.

You would not just follow others and may be even be able to see what is behind the things. ... Learning should primarily be based on other people's knowledge and wisdom, followed by your own personal views and understanding. They might be similar to those of others, but at least they are yours... S7

I think people are living to have their own views. ... I don't like to be told about something ... [I like] independent thinking, that is, you should have your own view towards the world. Otherwise you're wasting your life. S11

... Maybe I can explain it in my own way instead of recalling something [from textbook] word for word. ... I think if I can understand and solve it in my own way; that should be a good method. It's better than memorizing so much things. S12

One participant said that she had developed a sort of capacity to discern valuable viewpoints when faced with massive information. She was thus able to recognize whether others' sayings were valuable or worthless.

[My] understanding is different today from that in the past. At least, I think I now have my personal thinking geared towards some economic issues. I can differentiate between professional views and those that have no value, on the Internet. I think it's a kind of discernment. ST

\subsection{Conception E: Learning as Continuous and Informal Education Phenomena}

In the final category, it is found that subjects' conception of learning went beyond the classroom, and even their institution. They viewed learning as a general education phenomenon, which took place everywhere, and at any time, even during the entire course of their lives. They could be educated by practicing, participating in some activities - both in their university, and in real life situations. In addition, they highlighted the importance of interpersonal communication, which might include getting along with roommates, student colleagues, and strangers. As a result, their experiences were enriched, and their horizon, expanded. The value of this conception not only lay in the expanded circumstances for learning and enriched knowledge from every aspect of one's life, but also in the awareness of 
learning, at any time and in any place. Participants felt they would evolve into successful learners if they held on to this very holistic conception.

It became obvious that two students had expanded their definition of learning. Learning, for them, was a very extensive education phenomenon, and they believed it could happen all over the place.

I think the definition of learning is extensive. You can learn the skills you don't have, through life, course learning, and through reading books. S7

If you want to learn the society, for example, then you have to do an internship, engage in social work, or participate in a variety of activities as well as competitions. All of these are learning. S16

Their understanding of learning in this conception, however, went beyond the subject matter situation, and extended to interpersonal relationships, i.e., learning from other people's way of thinking, ways to deal with different situations and life styles. Several participants had highlighted the informal education phenomenon of learning from others, which occurred during their communication with others. In addition, some of them believed that this sort of learning could be a continuous process throughout one's life.

I think learning is a broad concept. Learning at the university is learning, but ... there is another one which is more important - what you have learnt from others. ... It is said that learning can continue throughout life. But it depends on how you define learning. It may not be possible if you only focus on textbook learning. But if you can learn from other people's behaviors, their way of talking, and how they led their lives, then it can go through the whole life. Now I truly feel that I have learnt something from others. S2

Additionally, I think it very important to learn from others. ... It's more about learning interpersonal communication. Now when I gradually enter the society, I can feel and perceive something which I had never felt before. I think I can touch some interpersonal issues and find both profound social relationship, and contradiction. S7

... actually what you learn is how to learn skills, how to communicate with others, how to work ... finally you realize what you should do. For example, you should know where to find the knowledge, ... and address questions to professionals regarding practical issues. S8

... then you deal with some things, you learn from the process, and from other people around you. That is the way he/she deals with something. Then you think that it is not so bad, and you can learn from it. $\quad$ S9

In the past, I think it was the reading and course learning that I called as learning. But now I discover that communicating with others and thinking about something is learning as well. ... At first, when you talk with somebody you can get some knowledge, not knowledge, but some information, [the way] they speak and the way deal with their affairs. Or, their affairs would provide you a new view towards others and towards yourself. S11 


\section{Discussion}

Clearly these qualitatively distinct ways of experiencing, oriented towards one common phenomenon of learning. Consequently, it could be inferred that the conceptions are relational, or more precisely, in a hierarchical manner (ÅKerlind, 2005b). Theoretically, the ways of experiencing obtained from phenomenographic study are able to represent a full range of opinions held by a group of people for a particular phenomenon at a specific time (ibid.). Phenomenographers are expected to figure out the hierarchical relationships among these ways of experiencing (Trigwell, 2006). The final product is called the 'outcome space' (Marton, 1986), which is shown below (Figure 1).

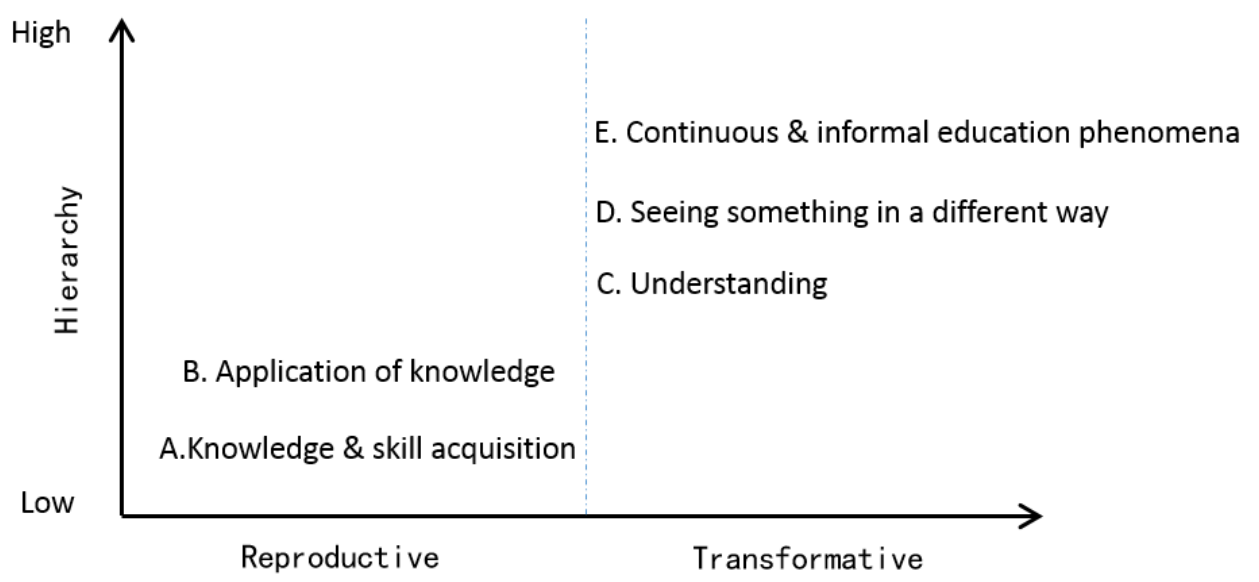

Figure 1. Outcome space for the research

While comparing the results of this study to that of Marton, Dall'Alba and Beaty's (1993) very influential research, one may discover two differences. The absence of viewing learning as memorization and reproduction is a significant one. Indeed, no participant in this investigation ever deliberately claimed that he/she understood learning as merely remembering pieces of knowledge. The other difference lay in the vacancy of change as a person. An offshoot, and perhaps an even more advanced conception drawn from this study was that learning is a series of continuous and informal education phenomena. The participants' conceptualization went beyond their institutional context, and they seemed to stay with the awareness of the process of learning all the time during their daily activities and in their lives. In this sense, the two conceptions - change as a person and continuous and informal education phenomena - share some commonalities. The remaining conceptions could be found in both studies.

The comparison made between the present study and the existing literature has generated theoretical implications. On the one hand, it proves that some of the conceptions are universal between research studies conducted in distinct contexts. On the other hand, it might be problematic to generalize some findings, since participants in a different world may view the same phenomenon differently. 
A and B are 'reproductive' conceptions, emphasizing what has been learnt. They regard learning as a process in which knowledge would be accumulated and reproduced (Duarte, 2007). By contrast, C, D, and E, are regarded as 'transformative', stressing the how aspect of learning and emphasizing understanding and interpreting the meanings (McLean, 2001). It is the 'meaning' (represented by the dotted line) that separates the two groups (Marton et al., 1993). The transformative categories seem to be more important than the reproductive ones, since they may influence students' personal life and career development (McLean, 2001). These conceptions stress the "what' or content aspects of learning and the 'how' aspect of learning which focus on process (how someone learns) and evidence (how someone knows they have learned)" (Peterson et al., 2010, p. 168). In line with Table 4, the set of categories are showing an increasingly inclusive nature, with more advanced categories containing some factors that less advanced ones do not involve.

A brief statistical analysis has also been made according to every conception's frequency. It has to be pointed out that each student may have probably expressed more than one conception; hence the percentage is not rounded. According to Table 4, only seven students have viewed learning as acquiring knowledge and skills, the simplest conceptions in this study. By contrast, understanding has been expressed by 14 participants, the highest percentage among all the conceptions.

Therefore, the practical significance of the study is embodied in Table 4, which indicates that most students were holding transformative conceptions and had better and deeper understanding towards the phenomenon of learning. This might positively influence their learning as a whole.

Table 4. Frequencies of conceptions

\begin{tabular}{lc}
\hline \multicolumn{1}{c}{ Conceptions } & Frequency \& Percentage \\
\hline Acquisition of knowledge and skills & $7(41 \%)$ \\
Application & $11(65 \%)$ \\
Understanding & $14(82 \%)$ \\
Seeing something in a different way & $8(47 \%)$ \\
Continuous and informal education phenomena & $9(53 \%)$ \\
\hline
\end{tabular}

\section{Conclusion}

While one may discover some similarity in findings made in this study and other research, it cannot be denied that Chinese students' ways of conceptualizing learning are somewhat different. The research verifies that conceptions of learning are contextually dependent; especially in those with distinct social, cultural, and historical traditions. It may be very problematic to blindly generalize findings made from one context to another. Likewise, researchers could not underestimate the value of cross-cultural research done in different contexts. 
The major limitation for the present study is that the sample could not fully represent all the undergraduates in Chinese higher education. Thus more empirical works are needed, and the disciplinary context should be more diverse. In addition, there is a significant drawback for the research approach adopted. In phenomenographic studies, researchers are not allowed to explore the reasons for certain conceptions held by participants (Lucas, 1998). Therefore, other studies may be encouraged to fill in the gap.

\section{References}

Åkerlind, G. S. (2005a). Academic growth and development-How do university academics experience it?. Higher Education, 50(1), 1-32.

ÅKerlind, G. S. (2005b). Learning about phenomenography: Interviewing, data analysis and the qualitative research paradigm. In J. Bowden \& P. Green (eds). Doing developmental phenomenography, Melbourne. RMIT University Press.

ÅKerlind, G., Bowden, J. A., \& Green, P. (2005). Learning to do phenomenography: A reflective discussion. In J. Bowden \& P. Green (eds). Doing developmental phenomenography, Melbourne. RMIT University Press.

Asikainen, H., Virtanen, V., Parpala, A., \& Lindblom-Ylänne, S. (2013). Understanding the variation in bioscience students' conceptions of learning in the 21st century. International Journal of Educational Research, 62, 36-42. http://dx.doi.org/10.1016/j.ijer.2013.06.010

Barnard, A., McCosker, H., \& Gerber, R. (1999). Phenomenography: a qualitative research approach for exploring understanding in health care. Qualitative Health Research, 9(2), 212-226.

Beaty, E., Dall'Alba, G., \& Marton, F. (1997). The personal experience of learning in higher education: changing views and enduring perspectives. In P. Sutherland (ed). Adult Learning: A Reader. Kogan Page Ltd., 22883 Quicksilver Drive, Sterling, VA 20166.

Biggs, J. (1996). Western misconceptions of the Confucian-heritage learning culture. In D. Watkins \& J. B. Biggs (eds), The Chinese learner: Cultural, psychological, and contextual influences. Hong Kong: CERC \& ACER.

Booth, S. A. (1992). Learning to program: A phenomenographic perspective. Göteborg: Acta Universitatis Gothoburgensis.

Byrne, M., \& Flood, B. (2004). Exploring the conceptions of learning of accounting students. Accounting Education, 13, 25-37. http://dx.doi.org/10.1080/0963928042000310779

Cope, C. (2004). Ensuring validity and reliability in phenomenographic research using the analytical framework of a structure of awareness. Qualitative Research Journal, 4(2), 5-18.

Dahlgren, L. O., \& Fallsberg, M. (1991). Phenomenography as a qualitative approach in social pharmacy research. Journal of Social and Administration Pharmacy, 8, 150-156.

Duarte, A. M. (2007). Conceptions of learning and approaches to learning in Portuguese students. Higher Education, 54, 781-794. http://dx.doi.org/10.1007/s10734-006-9023-7 
Edmunds, R., \& Richardson, J. T. (2009). Conceptions of learning, approaches to studying and personal development in UK higher education. British Journal of Educational Psychology, 79(2), 295-309. http://dx.doi.org/10.1348/000709908X368866

Ellis, R. A., Goodyear, P., Calvo, R. A., \& Prosser, M. (2008). Engineering students' conceptions of and approaches to learning through discussions in face-to-face and online $\begin{array}{llll}\text { contexts. Learning and Instruction, 267-282. } & \text { 18(3), }\end{array}$ http://dx.doi.org/10.1016/j.learninstruc.2007.06.001

Gibbs, G. (1995). Changing lecturers' conceptions of learning through action research. In A. Brew (Ed.), Directions in staff development. Buckingham, England: Society for Research in Higher Education and Open University Press.

Khan, S. H. (2014). Phenomenography: a qualitative research methodology in Bangladesh. International Journal on New Trends in Education \& their Implications (IJONTE), 5(2), 34-43.

Kinnunen, P., \& Simon, B. (2012). Phenomenography and grounded theory as research methods in computing education research field. Computer Science Education, 22(2), 199-218. http://dx.doi.org/10.1080/08993408.2012.692928

Lucas, U. (1998). Perceptions of Learning and Teaching Accounting: A Phenomenographic Study. Unpublished Doctoral Thesis, Sheffield Hallam University.

Marton, F. (1986). Phenomenography - a research approach to investigating different understandings of reality. Journal of thought, 28-49.

Marton, F. (1994). Phenomenography. In T. Husen \& N. Postlethwaite (Eds.), International Encyclopedia of Education. Oxford: Pergamon.

Marton, F., \& Booth, S. (1997). Learning and awareness. Mahwah, NJ: Lawrence Erlbaum Associates.

Marton, F., \& Dahlgren, L. O. (1976). On non-verbatim learning: The outcome space of some basic concepts in economics. Scandinavian Journal of Psychology, 17, 49-55.

Marton, F., Dall’Alba, G., \& Beaty, E. (1993). Conceptions of Learning. International Journal of Educational Research, 19, 277-300.

Marton, F., \& Pong, W. Y. (2005). On the unit of description in phenomenography. Higher education research \& development, 24(4), 335-348. http://dx.doi.org/10.1080/07294360500284706

Marton, F., Watkins, D., \& Tang, C. (1997). Discontinuities and continuities in the experience of learning: An interview study of high-school students in Hong Kong. Learning and instruction, 7(1), 21-48.

Maxwell, J. A. (1992). Understanding and validity in qualitative research. Harvard educational review, 62(3), 279-301. 
McLean, M. (2001). Can we Relate Conceptions of Learning to Student Academic Achievement?. Teaching in Higher Education, 6(3), 399-413. http://dx.doi.org/10.1080/13562510120061241

Mertens, D. M., \& McLaughlin, J. A. (2004). Research and evaluation methods in special education. Thousand Oaks, CA: Corwin Press.

Miyata, H., \& Kai, I. (2009). Reconsidering evaluation criteria for scientific adequacy in health care research: An integrative framework of quantitative and qualitative criteria. International Journal of Qualitative Methods, 8(1), 64-66.

Osborne, A. (2011). The value of information literacy: conceptions of BSc Nursing students at a UK university. Unpublished $\mathrm{PhD}$ thesis, University of Huddersfield.

Pang, M. F. (2003). Two faces of variation: On continuity in the phenomenographic movement. Scandinavian journal of educational research, 47(2), 145-156. http://dx.doi.org/10.1080/00313830308612

Peterson, E. R., Brown, G. T. L. \& Irving, S. E. (2010). Secondary school students' conceptions of learning and their relationship to achievement. Learning and Individual Differences, 20, 167-176. http://dx.doi.org/10.1016/j.lindif.2009.12.004

Pillay, H., \& Boulton-Lewis, G. (2000). Variations in conceptions of learning in construction technology: implications for learning. Journal of Education and Work, 13(2), 163-181. http://dx.doi.org/10.1080/713676984

Purdie, N. M., \& Hattie, J. (2002). Assessing students' conceptions of learning. Australian Journal of Educational and Developmental Psychology, 2, 17-32.

Säljö, R. (1979). Learning in the learner's perspective: I. Some common-sense assumptions (No.76). Göteborg: University of Göteborg, Institute of Education.

Säljö, R. (1987). The educational construction of learning. In J. T. E. Richardson, M. W. Eysenk \& D. W. Piper (Eds.), Student learning. Milton Keynes: Open University Press.

Säljö, R. (1988). Learning in Educational Settings: Methods of Inquiry. In P. Ramsden (Ed.), Improving Learning: New Perspectives. London: Kogan Page.

Sandbergh, J. (1997). Are phenomenographic results reliable?. Higher Education Research \& Development, 16(2), 203-212. http://dx.doi.org/10.1080/0729436970160207

Sandberg, J. (2000). Understanding human competence at work: an interpretative approach. Academy of management journal, 43(1), 9-25.

Sjöström, B. \& Dahlgren, L. O. (2002). Applying phenomenography in nursing research. Journal of Advanced Nursing, 40(3), 339-345.

Svensson, L. (1997). Theoretical foundations of phenomenography. Higher Education Research \& Development, 16(2), 159-171. http://dx.doi.org/10.1080/0729436970160204

Trigwell, K. (2006) Phenomenography: An approach to research into geography education. 


\section{Macrothink}

International Research in Education

ISSN 2327-5499 2015, Vol. 3, No. 2

Journal of Geography in Higher Education, 30(2), 367-372. http://dx.doi.org/10.1080/03098260600717489

Van Rossum, E. J., Deijkers, R., \& Hammer, R. (1985). Students' learning conceptions and their interpretation of significant educational concepts. Higher Education, 14, 617-641.

Van Rossum, E., \& Schenk, S. M. (1984). The relationship between learning conception, study strategy and learning outcome. British Journal of Educational Psychology, 54(1), 73-83.

Wen, Q. \& Marton, F. (1993) Chinese views on the relation between memorization and understanding. Paper presented at the 5th European Association for Research on Learning and Instruction Conference in Aix en Provence, August 31-September 5.

\section{Copyright Disclaimer}

Copyright reserved by the authors.

This article is an open-access article distributed under the terms and conditions of the Creative Commons Attribution license (http://creativecommons.org/licenses/by/3.0/). 